\title{
Isomerization of propargyl cation to cyclopropenyl cation: Mechanistic elucidations and effects of lone pair donors
}

\author{
ZODINPUIA PACHUAU, KIEW S KHARNAIOR and R H DUNCAN LYNGDOH* \\ Department of Chemistry, North-Eastern Hill University, Shillong 793 022, India \\ e-mail: rhdl@nehu.ac.in
}

MS received 29 December 2011; revised 20 August 2012; accepted 27 September 2012

\begin{abstract}
This ab initio study examines two pathways (one concerted and the other two-step) for isomerization of the linear propargyl cation to the aromatic cyclopropenyl cation, also probing the phenomenon of solvation of this reaction by simple lone pair donors $\left(\mathrm{NH}_{3}, \mathrm{H}_{2} \mathrm{O}, \mathrm{H}_{2} \mathrm{~S}\right.$ and $\left.\mathrm{HF}\right)$ which bind to the substrate at two sites. Fully optimized geometries at the B3LYP/6-31G(d) level were used, along with single point QCISD(T)/6$311+\mathrm{G}(\mathrm{d}, \mathrm{p})$ and accurate G3 level calculations upon the DFT optimized geometries. For the unsolvated reaction, the two-step second pathway is energetically favoured over the one-step first pathway. Lone pair donor affinity for the various $\mathrm{C}_{3} \mathrm{H}_{3}^{+}$species follows the uniform order $\mathrm{NH}_{3}>\mathrm{H}_{2} \mathrm{~S}>\mathrm{H}_{2} \mathrm{O}>\mathrm{HF}$. The activation barriers for the solvated isomerizations decrease in the order $\mathrm{HF}>\mathrm{H}_{2} \mathrm{O}>\mathrm{H}_{2} \mathrm{~S}>\mathrm{NH}_{3}$ for both pathways. The number of lone pairs on the donor heteroatom as well as the heteroatom electronegativity are factors related to both these trends. Compared to the unsolvated cases, the solvated reactions have transition states which are usually 'later' in position along the reaction coordinate, validating the Hammond postulate.
\end{abstract}

Keywords. Propargyl-cyclopropenyl cation isomerization; lone pair donor; solvent-substrate affinity; B3LYP QCISD(T); G3 calculations.

\section{Introduction}

Carbocations of the formula $\mathrm{C}_{3} \mathrm{H}_{3}^{+}$are an interesting field of study, since the cyclic isomer is the first member of the Hückel $4 n+2$ aromatic series. Relative stabilities of various $\mathrm{C}_{3} \mathrm{H}_{3}^{+}$structures have been studied theoretically, ${ }^{1,2}$ with location of four different structures. ${ }^{3,4}$ The cyclopropenyl cation $\left(\mathrm{c}-\mathrm{C}_{3} \mathrm{H}_{3}^{+}\right)$is the lowest in energy, while the propargyl cation $\mathrm{H}_{2} \mathrm{C}=\mathrm{C}=\mathrm{CH}^{+}$ lies $27.7 \mathrm{kcal} / \mathrm{mol}$ higher in energy, closely reproducing the experimental value of $25 \pm 4 \mathrm{kcal} / \mathrm{mol}^{3}$ for the energy difference.

Interest in the $\mathrm{C}_{3} \mathrm{H}_{3}^{+}$system also arises from the discovery of interstellar hydrocarbons, ${ }^{5-11}$ as well as the reactivity of $\mathrm{C}_{3} \mathrm{H}_{3}^{+}$in the moon Titan towards reactants in its atmosphere. ${ }^{12,13}$ Hydrocarbon ions as precursors for soot formation in flames have also attracted research, ${ }^{14-18}$ where soot formation was associated more with the linear propargyl cation than the cyclic isomer. ${ }^{18}$ Reaction with $\mathrm{C}_{2} \mathrm{H}_{2}$ led to isomerization of the linear isomer to the cyclic form, along with formation of $\mathrm{C}_{5} \mathrm{H}_{3}^{+}$and $\mathrm{C}_{5} \mathrm{H}_{5}^{+}$ions.

*For correspondence
This computational study probes the reaction of isomerization of the linear propargyl cation $\mathrm{H}_{2} \mathrm{C}=\mathrm{C}=\mathrm{CH}^{+}$ to the aromatic cyclopropenyl cation $\mathrm{c}-\mathrm{C}_{3} \mathrm{H}_{3}^{+}$for which two different mechanisms in gas phase have been postulated. ${ }^{1-4}$ This isomerization may be also accompanied by solvation by lone pair donors like $\mathrm{H}_{2} \mathrm{O}$, $\mathrm{HF}, \mathrm{H}_{2} \mathrm{~S}$ and $\mathrm{NH}_{3}$ which affect the energetic course of the reaction. Lui et al. ${ }^{19}$ used the $\operatorname{QCISD}(\mathrm{T}) / 6$ $311+\mathrm{G}(\mathrm{d}, \mathrm{p}) / / \mathrm{B} 3 \mathrm{LYP} / 6-31 \mathrm{G}(\mathrm{d})$ strategy to study the effects of $n \mathrm{H}_{2} \mathrm{O}$ molecules $(n=0,1,2,3)$ on the $\mathrm{C}_{3} \mathrm{H}_{3}^{+}$ system, predicting that water facilitates the isomerization reaction by relieving the reaction barrier. However, their data was misinterpreted in that solvation was mistaken for catalysis. Other studies include an MP4/6-311G(d,p)//MP2/6-31G(d) study $^{20}$ and a QCISD(T)/TZ3P//MP2/TZP study ${ }^{21}$ reporting specific pathways.

The two pathways proposed for the unsolvated isomerization are portrayed in figure 1, the first being concerted and the second a two-step route. The net reaction is exothermic owing to aromaticity of the cyclic isomer. The first pathway has one step (figure 1a) in which the propargyl cation 1 undergoes a 1,2 hydride shift. By numbering the carbon atoms in $\mathbf{1}$ as $\mathrm{C}^{1}, \mathrm{C}^{2}$ and $\mathrm{C}^{3}$, the cation 1 is represented as $\left[\mathrm{HC}^{1}=\mathrm{C}^{2}=\mathrm{C}^{3} \mathrm{H}_{2}\right]^{+}$where the $\mathrm{C}^{1}$ atom bears the formal unit positive charge. The $\mathrm{C}^{3}$ 
(a)
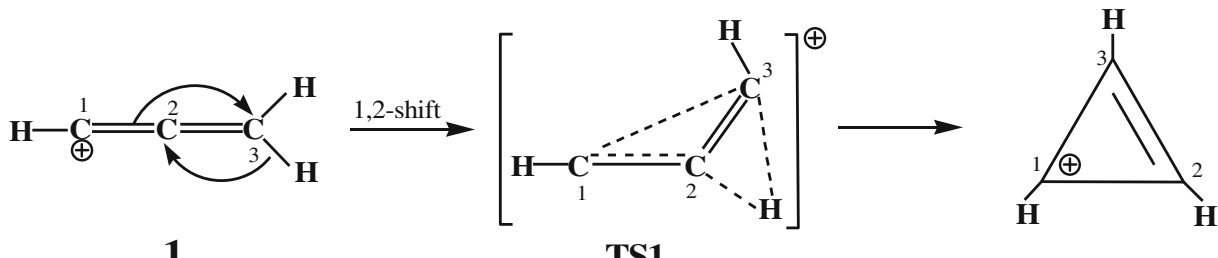

1

TS1
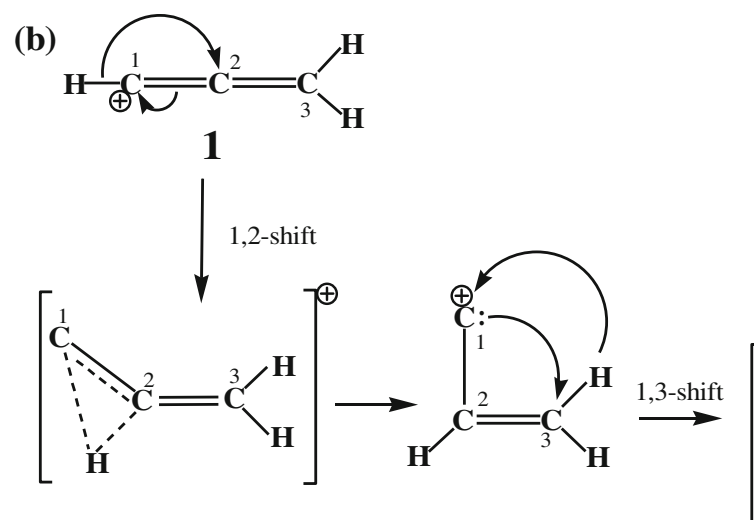

TS2

3

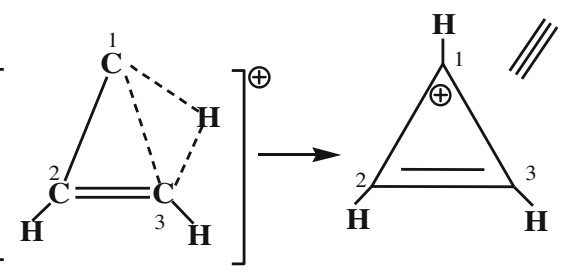

TS3

Figure 1. Unsolvated isomerization of propargyl cation to cyclopropenyl cation as given by (a) the first pathway and (b) the second pathway.

hydrogen migrates in 1,2 fashion to the $\mathrm{C}^{2}$ atom along with shift of the $C^{1}-C^{2}$ pi bond to give the new $C^{1}-C^{3}$ bond. The transition state TS1 is bicyclic, leading to the monocyclic cyclopropenyl cation product $\mathbf{2}$.

The second pathway involves two steps (figure 1b). The first step is a 1,2 hydride shift from the $\mathrm{C}^{1}$ to the $\mathrm{C}^{2}$ atom via transition state $\mathbf{T S} 2$ to give the unusual intermediate 3, written as $\left[: \mathrm{C}-\mathrm{CH}=\mathrm{CH}_{2}\right]^{+}$or $\left[: \mathrm{C}^{1}=\mathrm{C}^{2} \mathrm{H}-\right.$ $\left.\mathrm{C}^{3} \mathrm{H}_{2}\right]^{+}$, with the mono-coordinated $\mathrm{C}^{1}$ atom carrying the positive charge. Species 3 then undergoes 1,3 hydride shift from the $\mathrm{C}^{3}$ atom to the $\mathrm{C}^{1}$ atom via a bicyclic transition state TS3 to give the cyclopropenyl ion product 2.

It may be mentioned that the hydride shifts occurring in the above pathways could well involve quantum mechanical tunnelling effects, considering the small size of the hydride particle and the finding that some of the barriers involved are small. Even heavy atoms like the carbon atom have been predicted using the B3LYP method to undergo tunnelling during ring opening of the cyclopropylcarbinyl radical at low temperatures, ${ }^{22}$ which was confirmed by experimental results from intramolecular ${ }^{12} \mathrm{C} /{ }^{13} \mathrm{C}$ kinetic isotope effects. ${ }^{23}$ We have not yet undertaken such studies, although hydride tunnelling must be deemed a distinct possibility here.

The solvated versions of these two pathways employ the additional steps of binding of the lone pair donor
(LPD) or solvent to the substrate, and also the dissociation of the lone pair donor-product complex to yield the free cyclopropenyl cation product.

Solvation of the first pathway is shown in figure 2a. The LPD binds via its lone pair to the positive $\mathrm{C}^{1}$ atom of the substrate $\mathbf{1}$ giving a complex $\mathbf{C 1}$. This undergoes a 1,2 hydride shift from the $\mathrm{C}^{3}$ to the $\mathrm{C}^{2}$ atom via transition state TS4 giving the LPD-product complex $\mathbf{C 2}$. The LPD may use its lone pair(s) to push away the $\mathrm{C}^{1}-$ $\mathrm{C}^{2}$ pi bond electrons as they form the new $\mathrm{C}^{3}-\mathrm{C}^{1}$ bond. The LPD then leaves the $\mathrm{C}^{1}$ atom of the complex $\mathbf{C 2}$ to give the cyclopropenyl cation product 2 .

Solvation of the second mechanistic pathway involves two modes by which the LPD binds to the substrate. In the first association mode (figure 2b), the LPD binds to the $\mathrm{C}^{1}$ atom of the propargyl ion 1 to give the complex $\mathbf{C 1}$ (as in the first pathway). The next step is 1,2 hydride shift from the $\mathrm{C}^{1}$ atom to the $\mathrm{C}^{2}$ atom via transition state TS5 to give the intermediate ion $\left[: \mathrm{C}^{1}=\mathrm{C}^{2} \mathrm{H}-\mathrm{C}^{3} \mathrm{H}_{2}\right]^{+}$as a complex $\mathbf{C 3}$ with the LPD bound to the $\mathrm{C}^{1}$ atom. The LPD lone pair may assist this step by pushing away the nucleophilic hydride group from the $\mathrm{C}^{1}$ atom. This is followed by 1,3 hydride migration from the $\mathrm{C}^{3}$ atom to the $\mathrm{C}^{1}$ atom to give the LPD-product complex $\mathbf{C 2}$ (the same as for the first pathway) via transition state TS6. Complex $\mathbf{C 2}$ then dissociates to give the cyclopropenyl cation 2. 
(a)

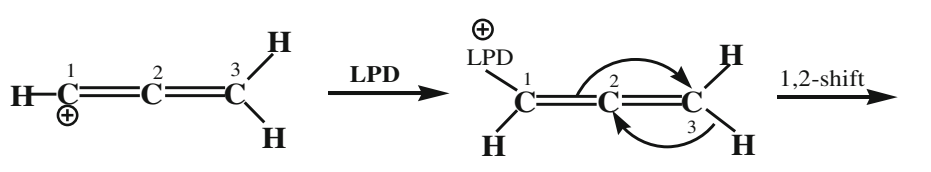

1

C1<smiles>OC1CCCC1</smiles>

TS4<smiles>C#CC1C2C=CC1C2C=C</smiles>

2<smiles>[C+]1C=CC1</smiles>

C2

(b)

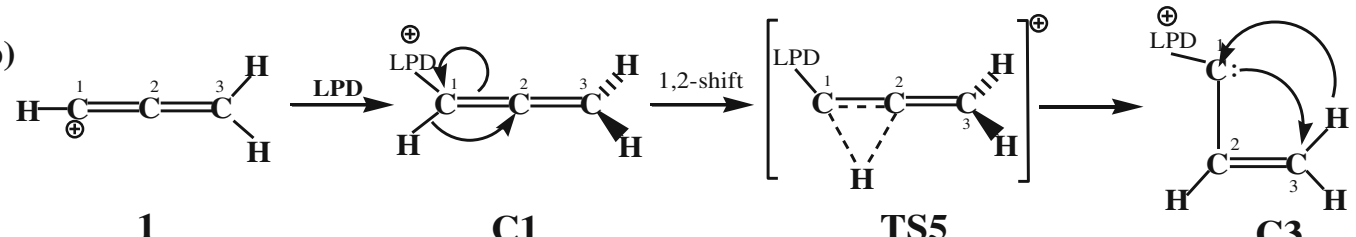

1<smiles></smiles>

2

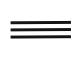<smiles>[CH]1[CH]C1</smiles><smiles>CCC[C@H]1C[C@H]1O</smiles>

$\mathrm{C2}$

C3

(c)

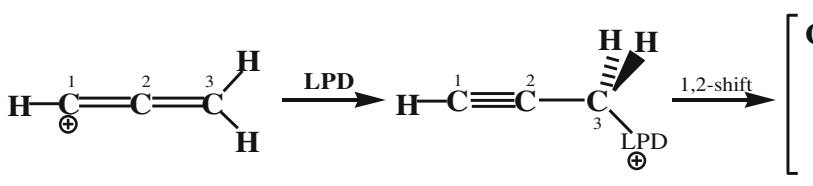

1

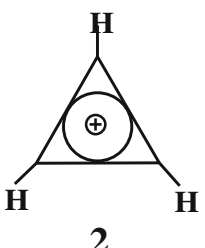

C4

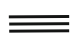

The second pathway also has a second association mode (figure $2 \mathrm{c}$ ), where the LPD binds to the $\mathrm{C}^{3}$ atom of $\mathbf{1}$ to form a complex $\mathbf{C 4}$. This undergoes 1,2 hydride shift from the $\mathrm{C}^{1}$ to the $\mathrm{C}^{2}$ atom via transition state TS7 to give the complex $\mathbf{C 5}$ where the LPD binds to the intermediate $\left[: \mathrm{C}^{1}=\mathrm{C}^{2} \mathrm{H}-\mathrm{C}^{3} \mathrm{H}_{2}\right]^{+}$at the $\mathrm{C}^{3}$ atom. The complex $\mathbf{C 5}$ then undergoes a 1,3 hydride shift from the $\mathrm{C}^{3}$ atom to the $\mathrm{C}^{1}$ atom via transition state TS8 to give the complex C2. The LPD then leaves $\mathbf{C 2}$ to give the cyclopropenyl cation 2.

Association of the LPD with various substrate/ transition state/product species may lend itself to further 
study through use of energy decomposition analysis ${ }^{24}$ which could yield further insight on the nature of such interactions. Unusual interactions benefit much from such studies, such as may be found in association of the LPD with the unusual intermediate $\left[: \mathrm{C}^{1}=\mathrm{C}^{2} \mathrm{H}-\mathrm{C}^{3} \mathrm{H}_{2}\right]^{+}$ at the $\mathrm{C}^{3}$ atom (figure 2c). Decomposition of interaction energies has been carried out using a variety of $a b$ initio methods to study radical dimers ${ }^{25}$ in the context of studying the role of multi-centred bonding for magnetic interactions in the pi-stacked bis-thiazolyl radical, where energy partitioning into electrostatic, orbital overlap, spin repulsion and dispersion contributions was performed. Such approaches are envisioned by us for further more detailed work. This study focuses primarily on net interaction energies and affinities between the LPD and the substrate without examining for contributory terms.

\section{Computational approach}

Energy-minimized equilibrium geometries were obtained by the B3LYP DFT method ${ }^{26-28}$ using the 6$31 \mathrm{G}(\mathrm{d})$ basis set. Transition states (TS) were obtained by refining model structures obtained from AM1 calculations. ${ }^{29}$ Vibrational frequency analyses confirmed a given structure as an energy minimum or a transition state, and also yielded zero-point energy (ZPE) corrections to the B3LYP total energy for all species. These calculations were done with the GAUSSIAN 98 set of programs. ${ }^{30}$ The B3LYP/6-31G(d) optimized geometries were further subjected to single-point calculations at the QCISD(T) level using the 6-311+G(d,p) basis set. Single point calculations were repeated using the highly accurate G3 level of theory ${ }^{31}$ with the G3B3 keyword of the GAUSSIAN 98 program.

This study focuses primarily on the energetics of the various reactions considered. The energy change $\Delta E_{r}$ for any one-step reaction is given as

$$
\Delta E_{r}=\Sigma\left[E_{t}(\operatorname{product}(\mathrm{s}))\right]-\Sigma\left[E_{t}(\text { reactants })\right],
$$

where the $E_{t}$ terms refer to the ZPE-corrected total energies calculated for each species. The activation barrier $E_{a}$ for a one-step reaction is the difference in ZPEcorrected total energies between transition state and reactant(s). The affinity $\Delta E_{\text {aff }}$ between an LPD and substrate is the negative of the interaction energy between the two, given in general as

$$
\Delta E_{a f f}=\left[E_{t}(\mathrm{LPD})+E_{t}(\text { substrate })\right]-E_{t}(\text { complex }) .
$$

Finally, for the solvated pathways, the energy term $\Delta E$ (TS) for any solvated transition state $\mathbf{T S}$ is calculated relative to the original substrate $\mathbf{1}$ and the LPD, being given as

$$
\Delta E(\mathrm{TS})=E_{t}(\mathrm{TS})-\left[E_{t}(1)+E_{t}(\mathrm{LPD})\right] .
$$

\subsection{Unsolvated pathways}

The unsolvated one-step first pathway (figure 1a) is characterized by an energy change $\Delta E_{r}(1)$ and an activation barrier $E_{a}(1)$. The unsolvated second pathway (figure 1b) has two steps. For the first step, the energy change is $\Delta E_{r}(2)$ and activation barrier $E_{a}(2)$; in the second step, the reaction enthalpy is $\Delta E_{r}(3)$ with an activation barrier $E_{a}(3)$.

\subsection{Solvated first pathway}

The reaction course (figure 2a) consists of (a) binding of the LPD to substrate $\mathbf{1}$ forming a complex $\mathbf{C 1}$, the LPDsubstrate affinity being given by the term $\Delta E_{\text {aff }}(\mathrm{C} 1)$, which is the negative of the energy change for this step, (b) the LPD-bound transition state TS4, characterized by the activation barrier $E_{a}$ (TS4) relative to complex C1, and the energy difference $\Delta E$ (TS4) between TS4 and the free species (1 plus LPD infinitely apart), (c) the LPD-bound complex $\mathbf{C} \mathbf{2}$ characterized by the affinity term $\Delta E_{\text {aff }}(\mathrm{C} 2)$, and (d) decomposition of the complex C2 to give the free product $\mathbf{2}$ and lone pair donor.

\subsection{Solvated second pathway (first association mode)}

The reaction course (figure $2 b$ ) consists of (a) binding of the LPD to 1 at the C1-atom forming the complex C1, (b) the LPD-bound transition state TS5 characterized by the energy difference $\Delta E$ (TS5) between TS5 and the free species 1 plus LPD infinitely apart, and also by the activation barrier $E_{a}$ (TS5) relative to the complex $\mathbf{C 1}$, (c) formation of the complex $\mathbf{C 3}$ having the affinity term $\Delta E_{\text {aff }}(\mathrm{C} 3)$, (d) the LPD-bound transition state TS6 characterized by the energy difference $\Delta E$ (TS6) between TS6 and the free species 1 plus LPD infinitely apart, and also by the activation barrier $E_{a}$ (TS6) relative to the complex $\mathbf{C 3}$, (e) formation of complex $\mathbf{C 2}$ with the affinity term $\Delta E_{a f f}(\mathrm{C} 2)$, and (f) decomposition of complex $\mathbf{C} \mathbf{2}$ to give the product $\mathbf{2}$ and LPD infinitely apart.

\subsection{Solvated second pathway (second association mode)}

The reaction course (figure 2c) consists of (a) binding of the LPD to 1 at the $\mathrm{C} 3$-atom to form the complex $\mathbf{C 4}$, 
(a)

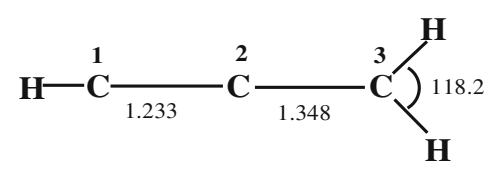

1

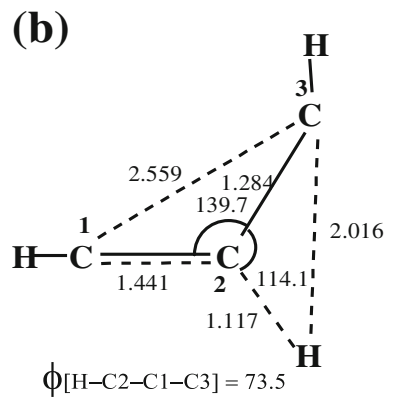

TS1

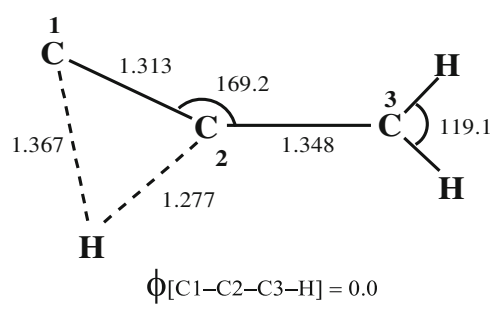

TS2

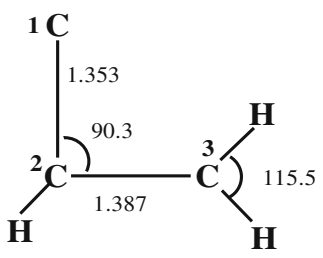

3

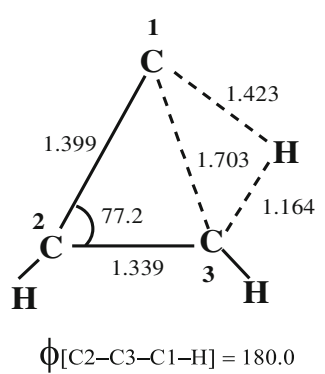

TS3

Figure 3. B3LYP structures for (a) $\mathrm{C}_{3} \mathrm{H}_{3}^{+}$isomers $\mathbf{1}, \mathbf{2}$ and $\mathbf{3}$, and (b) transition states TS1, TS2 and TS3 (all in unsolvated phase). Bond lengths in $\AA$, angles in degrees.

(b) the LPD-bound transition state TS7 characterized by the energy difference $\Delta E$ (TS7) between TS7 and the free species 1 plus LPD infinitely apart, and also by the activation barrier $E_{a}$ (TS7) relative to the complex C4, (c) formation of the complex $\mathbf{C 5}$ having the affinity term $\Delta E_{a f f}(\mathrm{C} 5)$, (d) the LPD-bound transition state TS8 characterized by the energy difference $\Delta E$ (TS8) between TS8 and the free species 1 plus LPD infinitely apart, and also by the activation barrier $E_{a}$ (TS8) relative to the complex $\mathbf{C 3}$, (e) formation of complex $\mathbf{C 2}$ having the affinity term $\Delta E_{a f f}(\mathrm{C} 2)$, and (f) decomposition of the complex $\mathbf{C} 2$ to give the free product $\mathbf{2}$ and LPD infinitely apart.

\subsection{Geometry parameters}

Geometry parameters include bond lengths, bond angles and dihedral angles (indicated by the term $\varphi$ with concerned atoms) as portrayed in figure 3 for the unsolvated species, in figures S2, S3, S5, S6 and S7 (supplementary information) for the various complexes and in figures 4 to 8 for the transition states. Such geometrical
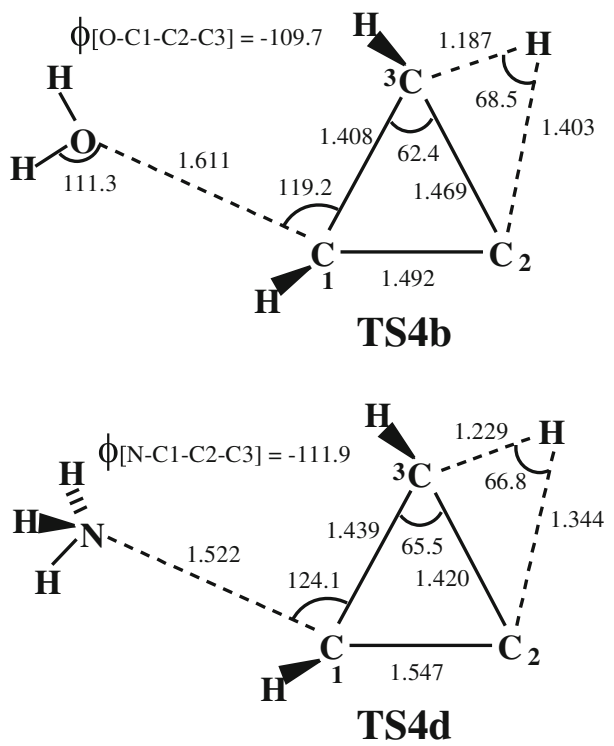

Figure 4. B3LYP structures for the TS4 transition state series. Bond lengths in $\AA$, angles in degrees. 


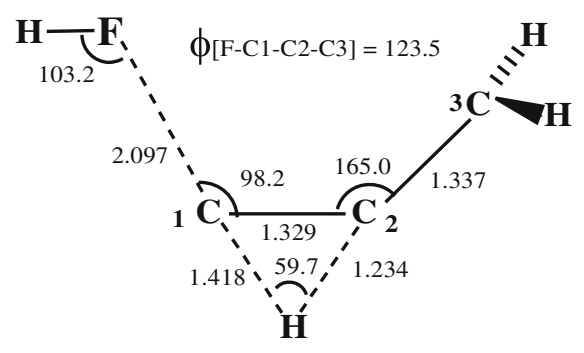

TS5a

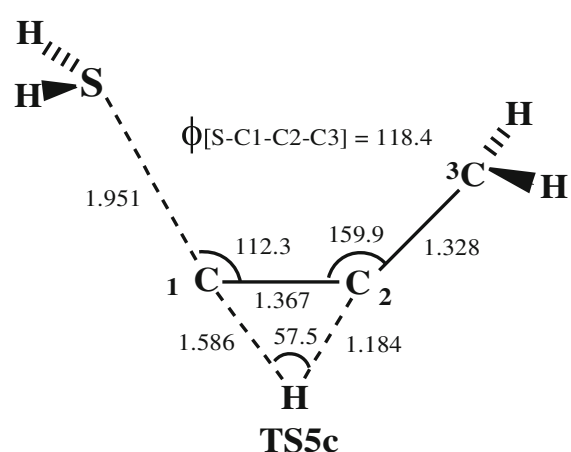

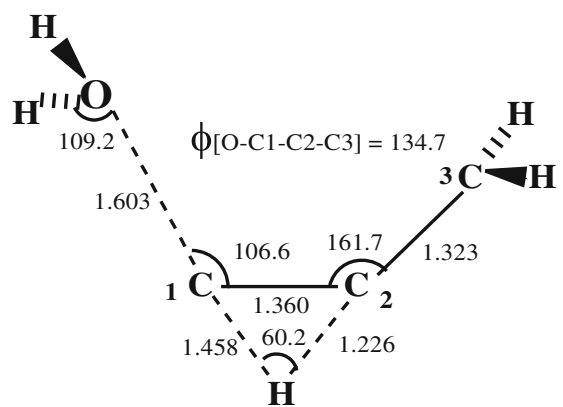

TS5b

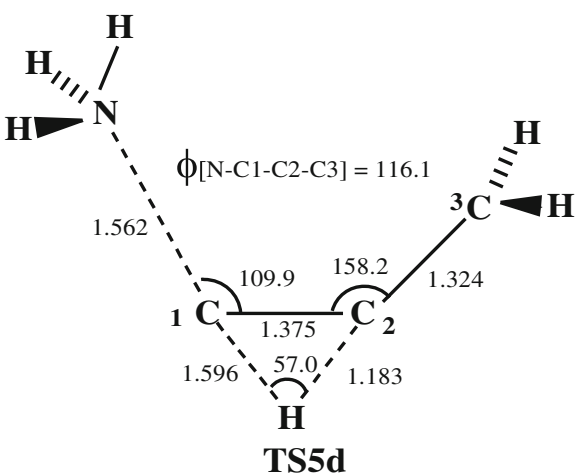

Figure 5. B3LYP structures for the TS5 transition state series. Bond lengths in $\AA$, angles in degrees.

characteristics can give clues to the nature of bonding between substrate and LDP in the complexes, and also regarding the extent of bond breaking or formation in the transition states.

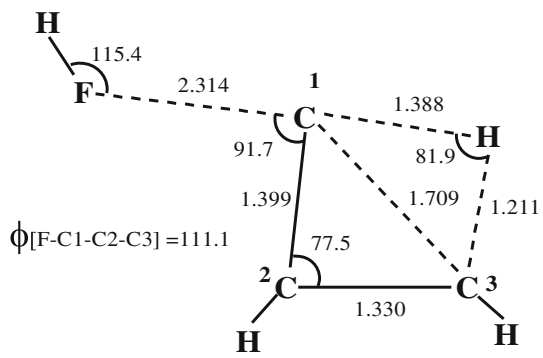

TS6a

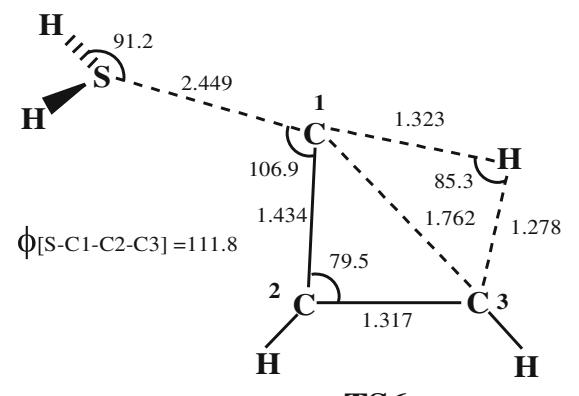

TS6c
Transition state geometries are interesting in the context of Hammond's postulate. ${ }^{32}$ This states that the energy and geometry of a transition state in an exothermic reaction (with a moderate activation barrier)

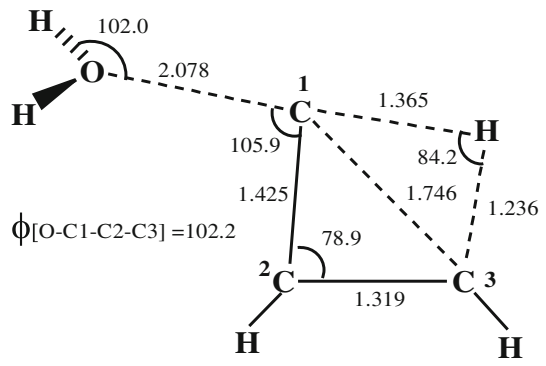

TS6b

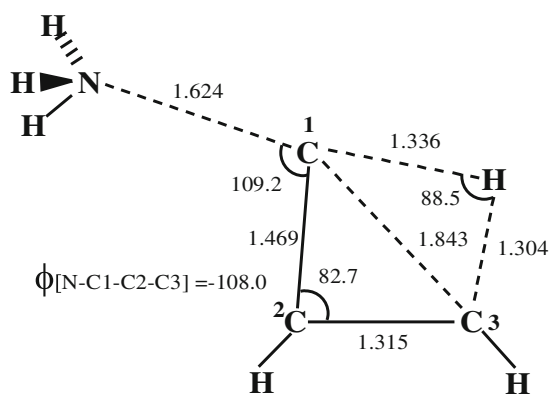

TS6d

Figure 6. B3LYP structures for the TS6 transition state series. Bond lengths in $\AA$, angles in degrees. 

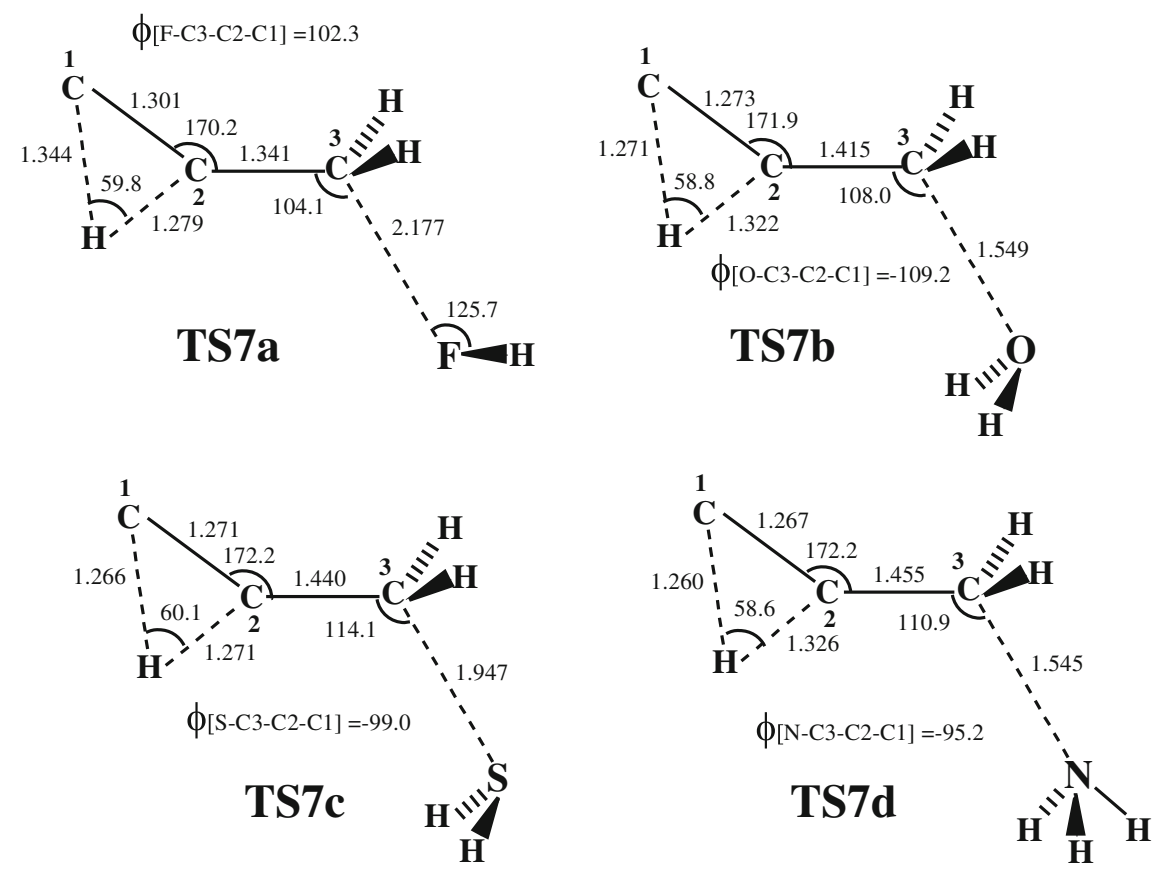

Figure 7. B3LYP structures for the TS7 transition state series. Bond lengths in $\AA$, angles in degrees.

tend to resemble those of the reactant, being termed 'early'. Conversely, the transition state in an endothermic reaction is 'late', tending to resemble the product. Geometrical criteria for 'earliness' and 'lateness' may be devised, where the relative position of the transition
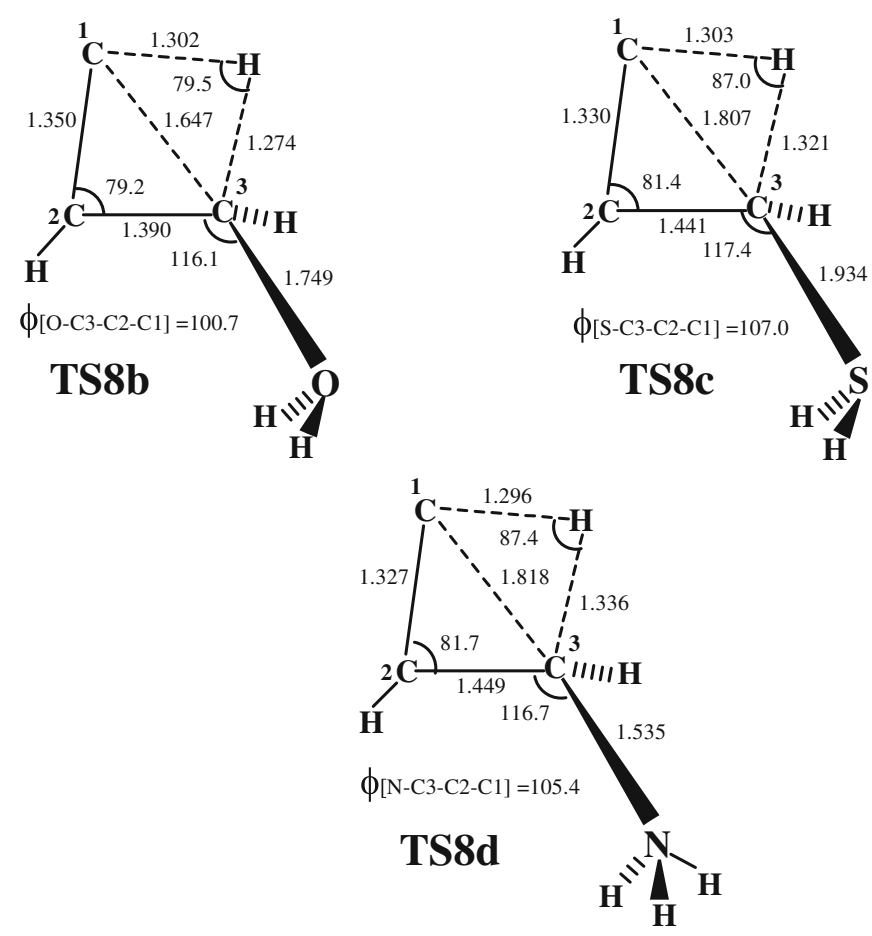

Figure 8. B3LYP structures for the TS8 transition state series. Bond lengths in $\AA$, angles in degrees. state along the reaction coordinate may be described in terms of the ratio of the length of the breaking bond to that of the forming bond, where smaller values point to 'earliness' and vice versa. Such an approach has been carried out using semi-empirical MO theory for alkyl group migration reactions in carbenes and carbocations. $^{33,34}$

\section{Results and discussion}

Energetics of the isomerization reactions are considered from the point of view of the activation barriers involved as well as the enthalpy changes associated with each step. Both mechanistic pathways described above are studied here in their unsolvated and solvated forms. Apart from the substrate, product and transition states involved, the complexes formed between the lone pair donors $\mathrm{HF}, \mathrm{H}_{2} \mathrm{O}, \mathrm{H}_{2} \mathrm{~S}$ and $\mathrm{NH}_{3}$ and the various $\mathrm{C}_{3} \mathrm{H}_{3}^{+}$species during the solvated pathways are also considered. The cases involving solvation by $\mathrm{HF}, \mathrm{H}_{2} \mathrm{O}$, $\mathrm{H}_{2} \mathrm{~S}$ and $\mathrm{NH}_{3}$ are defined by the letters a, b, $\mathbf{c}$ and $\mathbf{d}$, respectively.

Table S1 (see supplementary information) presents the B3LYP total energies and zero point energy (ZPE) corrections, along with the ZPE-corrected total energies obtained for all energy minima considered in this study by the B3LYP, QCISD(T) and G3 methods. The species include the unsolvated isomers 1, 2 and 3 along with the solvated species. The latter are grouped according to the 
LPD concerned, and include the stages of the $\mathrm{C}_{3} \mathrm{H}_{3}^{+}$isomers $\mathbf{1}$ and $\mathbf{2}$ each infinitely apart from the LPD, as well as the LPD-substrate complexes C1, C2, C3, C4 and C5. The ZPE corrections in each case are derived from the B3LYP calculations. The same approach is used to treat the various transition states encountered for the onestep reactions. The variously calculated total energies for these species are given in table S2 (supplementary information) which lists the total energies for the unsolvated transition states TS1, TS2 and TS3, as well as for the solvated counterparts TS4, TS5, TS6, TS7 and TS8.

\subsection{Unsolvated isomerization}

The two pathways for unsolvated isomerization are portrayed in figure $1 \mathrm{a}$ and $\mathrm{b}$. Table 1 presents the B3LYP, QCISD(T) and G3 values of the reaction energy change $\Delta E_{r}$ and the activation barrier $E_{a}$ associated with each step. The net isomerization enthalpy $\Delta E_{r}(1)$ is negative at all levels of theory, with values in $\mathrm{kcal} / \mathrm{mol}$ of -25.27 (B3LYP), -26.61 [QCISD(T)] and -24.80 (G3). These values are close to the reported experimental value $\mathrm{e}^{3}$ of $-25 \pm 4 \mathrm{kcal} / \mathrm{mol}$. The negative sign for $\Delta E_{r}(1)$ arises from stabilization through gain of aromaticity, which offsets the destabilizing effects of strain. The activation barrier $E_{a}(1)$ for the unsolvated first pathway via the bicyclic transition state TS1 is large, having values in $\mathrm{kcal} / \mathrm{mol}$ of 93.78 (B3LYP), 87.37 [QCISD(T)] and 82.61 (G3). This large barrier is associated with the strain encountered upon cyclization of the linear propargyl cation $\mathbf{1}$ to the cyclic isomer $\mathbf{2}$ via the bicyclic transition state TS1.

For the unsolvated second pathway, the activation barrier $E_{a}(2)$ for the first step (1,3-hydride migration forming intermediate 3 ) is quite appreciable, having values in $\mathrm{kcal} / \mathrm{mol}$ of 51.35 (B3LYP), 48.50 [QCISD(T)] and $47.98 \mathrm{kcal} / \mathrm{mol}$ (G3). These values are close to the value of $49.3 \mathrm{kcal} / \mathrm{mol}$ obtained for this step by Maluendes et $a l^{21}$ using the QCISD(T)/TZ3P//MP2/TZP approach. The high energy of the ionized carbene-like intermediate 3 relative to the propargyl cation is indicated by the energy change $\Delta E_{r}(2)$ with values in $\mathrm{kcal} / \mathrm{mol}$ of 44.37 (B3LYP), 40.75 [QCISD(T)] and 42.70 (G3). The high energy of $\mathbf{3}$ is due to the monovalent $\mathrm{C}^{1}$-atom present, so that $\mathbf{3}$ may be considered as a highly unstable ionized carbene-like species. The second step of the second pathway (1,2-hydride migration to form the product 2) has a small activation barrier $E_{a}(2)$ with values in $\mathrm{kcal} / \mathrm{mol}$ of 2.60 (B3LYP), 0.27 [QCISD(T)] and -1.30 (G3), which compare well with the value of $0.1 \mathrm{kcal} / \mathrm{mol}$ obtained by Maluendes et al. ${ }^{21}$ The G3 negative value for $E_{a}(2)$ arises out of the single point strategy employed as well as the use of a ZPE correction at the B3LYP level; the ZPE-uncorrected G3 value is $0.01 \mathrm{kcal} / \mathrm{mol}$. The first step is thus the ratedetermining one. The second step is virtually without a barrier, where transition state TS2 appears as a mere ripple on the potential energy surface leading to the low energy minimum $\mathrm{c}-\mathrm{C}_{3} \mathrm{H}_{3}^{+}$or $\mathbf{2}$.

We note that the first pathway (with a G3 barrier of $82.61 \mathrm{kcal} / \mathrm{mol}$ ) is predicted to be appreciably less feasible than the rate-determining step for the second pathway (with a G3 barrier of only $47.98 \mathrm{kcal} / \mathrm{mol}$ ). Free unsolvated isomerization of propargyl ion to the cyclopropenyl ion is therefore more likely to proceed by the second (two-step) pathway.

B3LYP equilibrium geometries of the species $\mathbf{1}, \mathbf{2}$ and $\mathbf{3}$ are represented in figure $3 \mathrm{a}$. The linearity of the propargyl cation 1 indicates $s p$ hybridized $\mathrm{C}^{1}$ and $\mathrm{C}^{2}$ atoms, with the $C^{1}-C^{2}$ bond shorter than the $C^{2}-C^{3}$ bond (since the $\mathrm{C}^{3}$ atom is $s p^{2}$ ). The most stable cyclopropenyl cation isomer $\mathbf{2}$ has planar $D_{3 h}$ symmetry in line with its fully delocalized aromatic structure, having $\mathrm{C}-\mathrm{C}$ bond lengths of $1.366 \AA$. The unstable intermediate $\mathbf{3}$ is also planar, where the $\mathrm{C}^{1}-\mathrm{C}^{2}-\mathrm{C}^{3}$ bond angle of $90.3^{\circ}$ seems to indicate an almost pure unhybridized $\mathrm{C}^{2}$ atom. The $\mathrm{C}^{1}-\mathrm{C}^{2}$ bond $(1.353 \AA$ ) is shorter than the $\mathrm{C}^{2}-\mathrm{C}^{3}$ bond (1.387 $\AA$ ), suggesting the ionized $\mathrm{C}^{1}$ atom has $s p$ character while the $\mathrm{C}^{3}$ atom is $s p^{2}$-hybridized.

Table 1. Energy changes and activation barriers for the unsolvated first and second pathways calculated by the B3LYP, QCISD(T) and G3 methods*.

\begin{tabular}{lrrrrrr}
\hline & \multicolumn{3}{c}{ Reaction energy change $\Delta E_{r}$} & & \multicolumn{3}{c}{ Activation barrier $E_{a}$} \\
\cline { 2 - 3 } \cline { 5 - 6 } Pathway and step & B3LYP & QCISD(T) & G3 & & B3LYP & QCISD(T) \\
\hline First pathway (single step) & -25.27 & -26.61 & -24.80 & & 93.78 & 87.37 \\
Second pathway (first step) & 44.37 & 40.75 & 42.70 & 51.35 & 48.50 & 82.61 \\
Second pathway (second step) & -69.64 & -67.36 & -67.50 & 2.60 & 0.27 & -1.30 \\
\hline
\end{tabular}

*All energy terms in $\mathrm{kcal} / \mathrm{mol}$ 
B3LYP geometries of the transition states TS1, TS2 and TS3 are represented in figure 3b. Structure TS1 for the one-step first pathway is bicyclic and strained, with the $\mathrm{C}^{1}-\mathrm{C}^{3}-\mathrm{H}$ and the $\mathrm{C}^{1}-\mathrm{C}^{2}-\mathrm{C}^{3}$ ring moieties at a dihedral angle of $73.5^{\circ}$ to each other, the $\mathrm{C}^{2}-\mathrm{H}-\mathrm{C}^{3}$ angle being markedly acute. The 'early' nature of TS1 is seen from the $C^{1}-C^{2}-C^{3}$ angle of $139.7^{\circ}$ and the $\mathrm{C}^{1}-\mathrm{C}^{3}$ bond length of $2.559 \AA$ (closer to the reactant than to the product in geometry), agree well with the exothermicity of this step. Transition state TS2 for the first step of the second pathway is planar and relatively 'late', with an $\mathrm{H}-\mathrm{C}^{2}$ bond length of $1.277 \AA$ and a $\mathrm{C}^{1}$ $\mathrm{H} / \mathrm{H}-\mathrm{C}^{2}$ bond length ratio of 1.070 ; this agrees well with the endothermicity of this step (with a G3 value of $42.70 \mathrm{kcal} / \mathrm{mol}$ ). TS3 is a planar bicyclic structure, and 'early' compared to TS2, with a $\mathrm{C}^{1}-\mathrm{H}$ bond length of $1.423 \AA$ and a $\mathrm{C}^{3}-\mathrm{H} / \mathrm{H}-\mathrm{C}^{1}$ bond length ratio of 0.818 . These assignments of 'early' or 'late' fit in well with what is expected from the magnitude and sign of the reaction enthalpies accompanying these changes as per Hammond's postulate.

\subsection{Solvated first pathway}

The solvated first pathway is portrayed in figure $2 b$, where the LPD's are $\mathrm{HF}, \mathrm{H}_{2} \mathrm{O}, \mathrm{H}_{2} \mathrm{~S}$ and $\mathrm{NH}_{3}$. The energy indices relevant for this pathway are presented in table 2. The LPD affinity $\Delta E_{a f f}(\mathrm{C} 1)$ for binding to the $\mathrm{C}^{1}$-atom of substrate $\mathbf{1}$ has a wide range of values, ranging from 0.18 to $66.88 \mathrm{kcal} / \mathrm{mol}(\mathrm{G} 3)$, and presents the order of magnitude $\mathrm{NH}_{3}>\mathrm{H}_{2} \mathrm{~S}>\mathrm{H}_{2} \mathrm{O}>\mathrm{HF}$ with respect to the LPD. This trend points to an effect of the number of lone pairs in the LPD upon substrate-LPD affinity, where $\mathrm{NH}_{3}$ has one lone pair, $\mathrm{H}_{2} \mathrm{~S}$ and $\mathrm{H}_{2} \mathrm{O}$ two lone pairs each, and HF three lone pairs. Increase in the number of lone pairs thus correlates with decrease in affinity. Electronegativity of the hetero-atom in the lone pair donor is another factor here, where the LPD with the most electronegative hetero-atom has the least affinity towards $\mathrm{H}_{2} \mathrm{CCCH}^{+}$and vice versa.

Table 2. LPD-substrate affinities for complexes $\mathbf{C 1}$ and C2 as calculated by the B3LYP, QCISD(T) and G3 methods*.

\begin{tabular}{lrrrrrrr}
\hline & \multicolumn{3}{c}{$\Delta E_{\text {aff }}(\mathrm{C} 1)$} & & \multicolumn{3}{c}{$\Delta E_{\text {aff }}(\mathrm{C} 2)$} \\
\cline { 2 - 3 } \cline { 7 - 8 } LPD & B3LYP & QCISD(T) & \multicolumn{1}{c}{ G3 } & & B3LYP & QCISD(T) & G3 \\
\hline $\mathrm{HF}$ & 11.74 & 1.20 & 0.18 & & 10.27 & 7.99 & 7.13 \\
$\mathrm{H}_{2} \mathrm{O}$ & 33.56 & 25.49 & 22.05 & & 14.03 & 11.88 & 9.53 \\
$\mathrm{H}_{2} \mathrm{~S}$ & 32.24 & 42.64 & 38.02 & & 13.77 & 6.55 & 5.26 \\
$\mathrm{NH}_{3}$ & 77.62 & 72.00 & 66.88 & & 40.46 & 37.94 & 32.66 \\
\hline
\end{tabular}

*Affinities in $\mathrm{kcal} / \mathrm{mol}$
Table 3 presents calculated values of the energy level $\Delta E$ (TS4) of the transition state TS4 with respect to the free species 1 plus LPD, ranging from 6.07 to $81.78 \mathrm{kcal} / \mathrm{mol}(\mathrm{G} 3)$. These $\Delta E(\mathrm{TS} 4)$ values are all lower than the activation barrier $E_{a}(1)$ of $82.61 \mathrm{kcal} / \mathrm{mol}$ (G3 value) for the unsolvated first pathway, and point to the effect of lowering the effective isomerization barrier relative to the unsolvated case. The $\mathrm{G} 3$ and QCISD(T) values for $\Delta E$ (TS4) values lead to the order $\mathrm{NH}_{3}>\mathrm{H}_{2} \mathrm{~S}>\mathrm{H}_{2} \mathrm{O}>\mathrm{HF}$ for capacity of the LPD to lower the activation barrier. This exactly reproduces the order obtained earlier for capacity of the LPD to bind to the substrate. This suggests that the capacity of an LPD to lower the transition state energy is linked to its affinity with the substrate, in turn dependent upon factors like the number of lone pairs contained as well as the electro-negativity of the hetero-atom involved.

The actual activation barrier $E_{a}(\mathrm{TS} 4)$ relative to the complex $\mathbf{C 1}$ (table 3) is, however, still quite large in all cases. The one-step route from $\mathbf{C} 1$ to $\mathbf{C 2}$ via TS4 gives the G3 values of $E_{a}(\mathrm{TS} 4)$ in $\mathrm{kcal} / \mathrm{mol}$ as 81.96 for the $\mathrm{HF}$ case, 80.67 for the $\mathrm{H}_{2} \mathrm{O}$ case, 74.50 for the $\mathrm{H}_{2} \mathrm{~S}$ case, and 72.95 for the $\mathrm{NH}_{3}$ case. These indicate that mere presence of the LPD does not appreciably lower the actual isomerization barrier encountered (still comparable to that for the unsolvated case). The LPD only lowers the energy level of the transition state TS4 with respect to the unsolvated case TS1, but does not appreciably reduce the actual activation barriers measured relative to the complex $\mathbf{C} \mathbf{1}$ itself taken as reactant.

The complex $\mathbf{C 2}$ or $\left[\left(\mathrm{c}-\mathrm{C}_{3} \mathrm{H}_{3}\right)-\mathrm{LPD}\right]^{+}$dissociates to give the cyclopropenyl cation product in all the pathways, regenerating the LPD. Table 2 presents variously calculated values for the LPD-product affinity $\Delta E_{a f f}(\mathrm{C} 2)$, where the $\mathrm{G} 3$ values in $\mathrm{kcal} / \mathrm{mol}$ are 7.13 for the HF case, 9.53 for the $\mathrm{H}_{2} \mathrm{O}$ case, 5.26 for the $\mathrm{H}_{2} \mathrm{~S}$ case, and 32.66 for the $\mathrm{NH}_{3}$ case. Comparison of values of $\Delta E_{a f f}(\mathrm{C} 1)$ and $\Delta E_{a f f}(\mathrm{C} 2)$ indicate that, except for the HF case, the LPD binds more effectively to the substrate $\mathbf{1}$ than to the product $\mathbf{2}$. This may be linked to the

Table 3. Energy terms* associated with the transition state TS4 calculated by the B3LYP, QCISD(T) and G3 methods.

\begin{tabular}{|c|c|c|c|c|c|c|}
\hline \multirow[b]{2}{*}{ LPD } & \multicolumn{3}{|c|}{$\Delta E(\mathrm{TS} 4)$} & \multicolumn{3}{|c|}{$E_{a}(\mathrm{TS} 4)$} \\
\hline & B3LYP & QCISD(T) & G3 & B3LYP & QCISD(T) & G3 \\
\hline $\mathrm{HF}$ & 72.82 & 81.90 & 81.78 & 84.56 & 83.11 & 81.96 \\
\hline $\mathrm{H}_{2} \mathrm{O}$ & 41.23 & 43.89 & 46.34 & 74.79 & 68.67 & 80.67 \\
\hline $\mathrm{H}_{2} \mathrm{~S}$ & 41.73 & 31.72 & 36.48 & 73.96 & 74.36 & 74.50 \\
\hline $\mathrm{NH}_{3}$ & 3.22 & 1.30 & 6.07 & 80.84 & 73.29 & 72.95 \\
\hline
\end{tabular}

*Energy terms in $\mathrm{kcal} / \mathrm{mol}$ 
greater positive charge on the $\mathrm{C}^{1}$-atom of the substrate $\mathbf{1}$ as compared to that on the carbon atoms of the product 2 (where charge is more effectively delocalized).

Figure S1 (supplementary information) depicts the G3 energy profile [with QCSID(T) values in brackets] for the unsolvated and solvated routes involved in the first pathway. Relative energies of each stage are compared, setting the initial stage (species 1 for the unsolvated pathway; species $\mathbf{1}$ plus LPD for the solvated pathway) at a zero energy level.

B3LYP geometries of the complex $\mathbf{C 1}$ between LPD and substrate $\mathbf{1}$ are represented in figure S2 (supplementary information) for the four cases C1a, C1b, C1c and C1d, where association occurs between the LPD hetero-atom $\mathrm{X}$ lone pair and the $\mathrm{C}^{1}$-atom. The $\mathrm{H}^{1}$ atom is now not collinear with the still almost linear $C^{1}-C^{2}-$ $\mathrm{C}^{3}$ moiety. The $\mathrm{C}^{1}$-atom now becomes an $s p^{2}$ hybrid, while the central $\mathrm{C}^{2}$ atom is still $s p$ hybridized. The dihedral $\phi\left[X-C^{1}-C^{2}-C^{3}\right]$ approaches $180^{\circ}$, indicating that atoms $\mathrm{C}^{3}, \mathrm{C}^{2}, \mathrm{C}^{1}$ and $\mathrm{X}$ are approximately coplanar; the $\mathrm{H}^{*}$ atom of the LPD is out of the $\mathrm{C}^{3}-\mathrm{C}^{2}-\mathrm{C}^{1}-\mathrm{X}$ plane. The $\mathrm{C}^{1}-\mathrm{X}$ distances (1.501 to $2.016 \AA$ ), all larger than usual covalently bonded $\mathrm{C}^{1}-\mathrm{X}$ distances in each case, show these bonds are not fully covalent in character. These distances give the order $\mathrm{HF}>\mathrm{H}_{2} \mathrm{~S}>\mathrm{H}_{2} \mathrm{O}>$ $\mathrm{NH}_{3}$, not related to the covalent radii of the heteroatoms $\mathrm{X}$, but related (inversely) to the order given for the affinity between LPD and substrate in $\mathbf{C 1}$ and $\mathbf{C 2}$.

Figure 4 depicts geometries for the transition state TS4 for the conversion of C1 to C2, where TS4a, TS4b,TS4c and TS4d correspond to the HF, $\mathrm{H}_{2} \mathrm{O}, \mathrm{H}_{2} \mathrm{~S}$ and $\mathrm{NH}_{3}$ cases. The structures are bicyclic and nonplanar (see $\varphi\left[\mathrm{X}-\mathrm{C}_{1}-\mathrm{C}_{2}-\mathrm{C}_{3}\right]$ values; cf. the corresponding structure TS1 for the unsolvated process). The LPD is not coplanar with the $C^{1}-C^{2}-C^{3}$ moiety, and the $C^{1}-X$ bond lengths range from 1.522 to $1.8147 \AA$, falling in the order $\mathrm{H}_{2} \mathrm{~S}>\mathrm{HF}>\mathrm{H}_{2} \mathrm{O}>\mathrm{NH}_{3}$. The LPD has the effect of making these transition states markedly 'later' in character compared to TS1. The carbocyclic moiety is close in geometry to the product $\mathbf{2}$, as seen from the $\mathrm{C}^{1}-\mathrm{C}^{3}$ bond lengths and the $\mathrm{C}^{1}-\mathrm{C}^{2}-\mathrm{C}^{3}$ bond angles (close to $60^{\circ}$ ). The $\mathrm{C}^{3}-\mathrm{H} / \mathrm{H}-\mathrm{C}^{2}$ bond length ratios for the TS4 species range from 0.622 to 0.927 , so that the relative degree of 'lateness' for the TS4 species as indicated by this ratio falls in the order $\mathrm{H}_{2} \mathrm{~S}>\mathrm{NH}_{3}>\mathrm{H}_{2} \mathrm{O}$ $>\mathrm{HF}$ with respect to the lone pair donor.

Figure S3 (supplementary information) gives geometries of complex $\mathbf{C 2}$ between LPD and product $\mathbf{2}$ for the four cases $\mathbf{C 2 a}, \mathbf{C 2 b}, \mathbf{C 2 c}$ and $\mathbf{C 2 d}$. The $\mathrm{C}^{1}-\mathrm{C}^{2}-$ $\mathrm{C}^{3}$ moiety clearly approaches the cyclic product $\mathbf{2}$ in geometry. The tetra-coordinated LPD-bonded $\mathrm{C}^{2}$ atom is a distorted $s p^{3}$ hybrid. The LPD's are positioned out of the carbocycle plane, as shown by values of the dihedral $\phi\left[\mathrm{X}-\mathrm{C}^{1}-\mathrm{C}^{2}-\mathrm{C}^{3}\right]$. The $\mathrm{C}^{1}-\mathrm{X}$ distances $(1.562$ to $3.066 \AA$ ), are longer than for the $\mathbf{C} \mathbf{1}$ complex in each case, giving the order $\mathrm{H}_{2} \mathrm{~S}>\mathrm{HF}>\mathrm{H}_{2} \mathrm{O}>\mathrm{NH}_{3}$.

\subsection{Solvated second pathway (first association mode)}

The solvated second pathway with the first association mode is depicted in figure $2 \mathrm{~b}$. The variously calculated values of the relevant energy indices for this reaction course are presented in tables 4 and 5. This pathway shares with the solvated first pathway the initial step of LPD binding to the $\mathrm{C}^{1}$-atom of $\mathbf{1}$ forming the complex C1. The details concerning this have already been discussed above for the solvated first pathway.

1,2-Hydride migration in complex $\mathbf{C} 1$ gives rise to the complex $\mathbf{C 3}$ via the transition state TS5. The TS5 species correspond to the transition state TS2 for the first step of the unsolvated second pathway. Table 4 lists values of the energy $\Delta E$ (TS5) of TS5 relative to the starting reactants (1 plus LPD) which range from -3.93 to $45.70 \mathrm{kcal} / \mathrm{mol}$ (G3 values).

These values are all lower than the G3 value of $47.98 \mathrm{kcal} / \mathrm{mol}$ for $E_{a}(2)$, the activation barrier for the corresponding first step of the unsolvated second pathway, and yield the order of magnitude $\mathrm{HF}>\mathrm{H}_{2} \mathrm{O}>\mathrm{H}_{2} \mathrm{~S}$ $>\mathrm{NH}_{3}$. The order reverse to this describes the relative effectiveness of the LPD to stabilize the transition state

Table 4. Energy terms associated with the transition state TS5 and LPD affinity for the complex C3 as calculated by the B3LYP, QCISD(T) and G3 methods*.

\begin{tabular}{|c|c|c|c|c|c|c|c|c|c|}
\hline \multirow[b]{2}{*}{ LPD } & \multicolumn{3}{|c|}{$\Delta E(\mathrm{TS} 5)$} & \multicolumn{3}{|c|}{$E_{a}(\mathrm{TS} 5)$} & \multicolumn{3}{|c|}{$\Delta E_{a f f}(\mathrm{C} 3)$} \\
\hline & B3LYP & QCISD(T) & G3 & B3LYP & QCISD(T) & G3 & B3LYP & QCISD(T) & G3 \\
\hline $\mathrm{HF}$ & 37.99 & 45.89 & 45.70 & 49.73 & 46.46 & 45.88 & 21.66 & 6.51 & 4.87 \\
\hline $\mathrm{H}_{2} \mathrm{O}$ & 24.32 & 29.26 & 32.42 & 57.88 & 56.01 & 54.47 & 43.79 & 32.63 & 29.22 \\
\hline $\mathrm{H}_{2} \mathrm{~S}$ & 23.61 & 18.41 & 21.76 & 55.84 & 62.05 & 59.79 & 40.86 & 40.03 & 36.41 \\
\hline $\mathrm{NH}_{3}$ & -9.31 & 0.05 & -3.93 & 68.31 & 65.08 & 62.96 & 74.92 & 68.04 & 62.97 \\
\hline
\end{tabular}

*Energy terms and affinities in $\mathrm{kcal} / \mathrm{mol}$ 
Table 5. Energy terms associated with the transition state TS6 calculated by the B3LYP, QCISD(T) and G3 methods*.

\begin{tabular}{lrrrrrrr}
\hline & \multicolumn{3}{c}{$\Delta E$ (TS6) } & & \multicolumn{3}{c}{$E_{a}($ TS6) } \\
\cline { 2 - 3 } \cline { 7 - 8 } LPD & B3LYP & QCISD(T) & G3 & & B3LYP & QCISD(T) & G3 \\
\hline $\mathrm{HF}$ & 35.75 & 35.23 & 36.49 & & 13.04 & 0.99 & 1.34 \\
$\mathrm{H}_{2} \mathrm{O}$ & 29.66 & 31.41 & 34.04 & & 29.07 & 22.34 & 20.57 \\
$\mathrm{H}_{2} \mathrm{~S}$ & 32.65 & 29.10 & 31.39 & & 29.13 & 28.38 & 25.10 \\
$\mathrm{NH}_{3}$ & 3.81 & 3.19 & 6.00 & & 34.35 & 30.48 & 26.27
\end{tabular}

*All energy terms in $\mathrm{kcal} / \mathrm{mol}$

TS5; this is the same as the order for LPD-substrate affinity in the complex C1. Table 4 also presents the actual activation barriers $E_{a}$ (TS5) relative to the complex C1, with values ranging from 45.88 to $62.96(\mathrm{G} 3)$, often larger than the G3 value of $47.98 \mathrm{kcal} / \mathrm{mol}$ for the unsolvated barrier $\mathrm{E}_{a}(2)$. This illustrates the point made earlier, viz., that the ability of an LPD to stabilize the transition state is reflected in the energy of the LPD-bound transition state relative to the free reactants ( 1 plus LPD) and not in the actual activation barrier encountered by the complex $\mathbf{C 1}$ itself acting as the reactant.

Complex C3 may be described as an LPD-bound intermediate corresponding to species $\mathbf{3}$ in the corresponding unsolvated second pathway. Table 4 gives the variously calculated values of the affinity $\Delta E_{a f f}(\mathrm{C} 3)$ between LPD and species 3 forming complex $\mathbf{C 3}$, with $\mathrm{G} 3$ values ranging from 4.87 to $62.97 \mathrm{kcal} / \mathrm{mol}$. The $\mathrm{G} 3$ and QCISD(T) methods give the general order $\mathrm{NH}_{3}>$ $\mathrm{H}_{2} \mathrm{~S}>\mathrm{H}_{2} \mathrm{O}>\mathrm{HF}$ for strength of binding between the LPD and 3.

The complex C3 encounters the transition state TS6 as it converts to the complex $\mathbf{C 2}$ in the second phase of the solvated second pathway (first association mode). Here, the TS6 species corresponds to transition state TS3 for the second step of the unsolvated second pathway. Table 5 gives the variously calculated values of the energy terms $\Delta E$ (TS6) and activation barriers $E_{a}$ (TS6) for the four solvated cases. The energy level $\Delta E$ (TS6) of the transition states TS6a, TS6b, TS6c and TS6d relative to the original reactants (1 plus the LPD) ranges from 6.00 to $36.49 \mathrm{kcal} / \mathrm{mol}$ (G3 values). Both the G3 and the QCISD(T) strategies yield the order $\mathrm{NH}_{3}<$ $\mathrm{H}_{2} \mathrm{~S}<\mathrm{H}_{2} \mathrm{O}<\mathrm{HF}$ for magnitude of the $\Delta E$ (TS6) term, the converse of which gives the relative capacity of the LPD's to stabilize TS6 with respect to the free reactants 1 plus LDP.

We may now compare the actual activation barriers $E_{a}$ (TS5) and $E_{a}$ (TS6) met by the complexes $\mathbf{C 1}$ and C3 in the first and second solvated steps, respectively. Their values show that, for the three cases of $\mathrm{HF}, \mathrm{H}_{2} \mathrm{O}$ and $\mathrm{H}_{2} \mathrm{~S}$, the first solvated step (C1 to $\mathbf{C 3}$ via TS5) is less feasible than the second solvated step $(\mathbf{C} 3$ to $\mathbf{C 2}$ via TS6). We may infer that the first step involving transition state TS5 is the rate determining step for the solvated second pathway (first association mode). This parallels the unsolvated case, where the first step is the rate determining one.

Figure S4 (supplementary information) depicts the G3 and QCISD(T) energy profiles for the unsolvated and solvated routes involved in the second pathway (first association mode), where relative energies of each stage may be compared, setting the initial stage (species 1 for the unsolvated pathway; species 1 plus LPD for the unsolvated pathways) at an energy level of zero.

Figure 5 schematically portrays the transition states TS5a, TS5b, TS5c and TS5d for conversion of complex $\mathbf{C 1}$ to complex $\mathbf{C 3}$ in the first step of the solvated second pathway (first association mode). The TS5 transition states correspond to the transition state TS2 for the first step of the unsolvated second pathway. The wide $\mathrm{C}^{1}-\mathrm{C}^{2}-\mathrm{C}^{3}$ angle values (ranging from 158.2 to $165.0^{\circ}$ ) seem to indicate that these transition states are 'early' and resemble the reactant (complex C1) rather than the product (complex C3). However, the breaking $\mathrm{C}^{1}-\mathrm{H}$ bond is uniformly longer (1.418 to $1.596 \AA$ ) than the forming $\mathrm{C}^{2}-\mathrm{H}$ bond (1.813 to $1.234 \AA$ ) in all these transition states. The $\mathrm{C}^{1}-\mathrm{H} / \mathrm{C}^{2}-\mathrm{H}$ bond length ratios yields the order $\mathrm{HF}>\mathrm{H}_{2} \mathrm{O}>\mathrm{H}_{2} \mathrm{~S}>\mathrm{NH}_{3}$ for 'earliness' of the TS5 transition state species; this same order also emerges for relative 'earliness' as indicated by the $\mathrm{C}^{1}-\mathrm{C}^{2}-\mathrm{C}^{3}$ bond angle.

Figure S5 (supplementary information) depicts the complexes C3a, C3b, C3c and C3d. The $\mathrm{C}^{1}-\mathrm{X}$ bond lengths range from 1.427 to $1.809 \AA$ and present the order $\mathrm{HF}>\mathrm{H}_{2} \mathrm{~S}>\mathrm{NH}_{3}>\mathrm{H}_{2} \mathrm{O}$ with respect to the LPD. This order does not correspond either to the covalent radii of the heteroatoms involved nor the affinity $\Delta E_{a f f}(\mathrm{C} 3)$ for this series of complexes. The heteroatom $\mathrm{X}$ lies in the same plane as the $\mathrm{C} 1, \mathrm{C} 2$ and $\mathrm{C} 3$ atoms.

Figure 6 depicts relevant geometry data for the bicyclic transition states TS6a, TS6b, TS6c and TS6d for rearrangement of complex $\mathbf{C 3}$ to complex $\mathbf{C 2}$. These transition states have the LPD out of the $\mathrm{C} 1-\mathrm{C} 2-\mathrm{C} 3$ plane (see $\varphi[\mathrm{X}-\mathrm{C} 1-\mathrm{C} 2-\mathrm{C} 3$ values $]$ and correspond to the transition state TS3 for the second step of the unsolvated second pathway. The TS6 species are all on the 'early' side, which fits in well with what is expected from the negative enthalpies calculated for this step (values not given); this is as per the Hammond postulate. The $\mathrm{C}^{3}-\mathrm{H} / \mathrm{C}^{1}-\mathrm{H}$ bond length ratios range from 0.873 to 0.976 and indicate the order $\mathrm{HF}>\mathrm{H}_{2} \mathrm{O}>$ $\mathrm{H}_{2} \mathrm{~S}>\mathrm{NH}_{3}$ for relative 'earliness' of the TS6 species in each case. 
Table 6. LPD-substrate affinity for the complex $\mathbf{C 4}$ and energy terms associated with the transition state TS7 as calculated by the B3LYP, QCISD(T) and G3 methods*.

\begin{tabular}{|c|c|c|c|c|c|c|c|c|c|}
\hline \multirow[b]{2}{*}{ LPD } & \multicolumn{3}{|c|}{$\Delta E_{a f f}(\mathrm{C} 4)$} & \multicolumn{3}{|c|}{$\Delta E(\mathrm{TS} 7)$} & \multicolumn{3}{|c|}{$E_{a}(\mathrm{TS} 7)$} \\
\hline & B3LYP & QCISD $(\mathrm{T})$ & G3 & B3LYP & QCISD $(\mathrm{T})$ & G3 & B3LYP & QCISD(T) & G3 \\
\hline $\mathrm{HF}$ & 12.59 & 4.74 & 2.78 & 38.14 & 42.78 & 43.26 & 50.73 & 47.52 & 46.04 \\
\hline $\mathrm{H}_{2} \mathrm{O}$ & 29.41 & 25.95 & 21.61 & 22.61 & 25.12 & 28.09 & 52.02 & 51.07 & 49.67 \\
\hline $\mathrm{H}_{2} \mathrm{~S}$ & 31.11 & 40.12 & 34.04 & 20.97 & 10.34 & 15.93 & 52.07 & 51.07 & 49.98 \\
\hline $\mathrm{NH}_{3}$ & 71.55 & 72.72 & 66.27 & -18.78 & -21.23 & -16.34 & 52.76 & 51.49 & 49.93 \\
\hline
\end{tabular}

*Affinities and energy terms in $\mathrm{kcal} / \mathrm{mol}$

\subsection{Solvated second pathway (second association mode)}

Figure $2 \mathrm{c}$ portrays the solvated second pathway with the second association mode where the LPD first binds to the $\mathrm{C}^{3}$-atom of the substrate $\mathbf{1}$ to give the complex C4. The relevant energy data for this pathway are given in table 6 . G3 values of the affinity term $\Delta E_{a f f}(\mathrm{C} 4)$ for complex $\mathbf{C 4}$ (in $\mathrm{kcal} / \mathrm{mol}$ ) are 2.78 for the $\mathrm{HF}$ case, 21.61 for the $\mathrm{H}_{2} \mathrm{O}$ case, 34.04 for the $\mathrm{H}_{2} \mathrm{~S}$ case, and 66.27 for the $\mathrm{NH}_{3}$ case. All three strategies predict the affinity order as $\mathrm{NH}_{3}>\mathrm{H}_{2} \mathrm{~S}>\mathrm{H}_{2} \mathrm{O}>$ $\mathrm{HF}$ with respect to the catalyst, suggesting once more an effect of the number of lone pairs on the catalyst upon the substrate-LPD affinity, as well as an effect of hetero-atom electronegativity.

In the first phase of this pathway, the complex $\mathbf{C 4}$ converts to the complex $\mathbf{C 5}$ via the LPD-bound transition state TS7. Table 6 presents the variously calculated values of the energy level $\Delta E$ (TS7) of TS7 relative to the starting reactants (1 plus LPD) which range from -16.34 to $43.26 \mathrm{kcal} / \mathrm{mol}$ (G3 values). These values are all lower than the $\mathrm{G} 3$ value of $42.70 \mathrm{kcal} / \mathrm{mol}$ for the energy level of TS2 in the corresponding first step of the unsolvated second pathway, and yield the order $\mathrm{NH}_{3}>$ $\mathrm{H}_{2} \mathrm{~S}>\mathrm{H}_{2} \mathrm{O}>\mathrm{HF}$ for effectiveness of the LPD to lower the energy level of TS7; this is the same as the order for LPD-substrate affinity in the complex C4. Table 6 also presents the actual activation barriers $E_{a}(\mathrm{TS} 7)$ relative to the complex $\mathbf{C 4}$, with $\mathrm{G} 3$ values ranging from 46.04 to $49.98 \mathrm{kcal} / \mathrm{mol}$, often larger than the G3 value of $47.98 \mathrm{kcal} / \mathrm{mol}$ for the unsolvated barrier $\mathrm{E}_{a}(2)$. This once again points to the observation that the ability of an LPD to lower the activation barrier is reflected in the energy of the LPD-bound transition state relative to the free reactants ( $\mathbf{1}$ plus catalyst) and not in the actual activation barrier encountered by the complex $\mathbf{C} \mathbf{4}$ itself acting as the reactant.

Table 7 presents the values for the affinity term $\Delta E_{\text {aff }}(\mathrm{C} 5)$ for the complex C5. The G3 values in $\mathrm{kcal} / \mathrm{mol}$ are 5.58 (HF case), $15.34\left(\mathrm{H}_{2} \mathrm{O}\right.$ case), 26.30 $\left(\mathrm{H}_{2} \mathrm{~S}\right.$ case $)$ and $58.36\left(\mathrm{NH}_{3}\right.$ case $)$. All three computational strategies predict that the capacity of the LPD to stabilize the intermediate 3 falls in the order $\mathrm{NH}_{3}>$ $\mathrm{H}_{2} \mathrm{~S}>\mathrm{H}_{2} \mathrm{O}>\mathrm{HF}$. Complex C5 is always less stable than the corresponding complex $\mathbf{C 3}$ (see table 4) indicating preference for LPD coordination to the $\mathrm{C}^{1}$ atom of intermediate 3 rather than to the $\mathrm{C}^{3}$ atom. This arises from greater affinity of the lone pair donors towards the ionized carbene-like $\mathrm{C}^{1}$ atom than towards the neutral $s p^{2}$ hybridized $\mathrm{C}^{3}$ atom of species 3 .

Figure S6 (supplementary information) depicts the C4 series of LPD complexes with substrate $\mathbf{1}$ in the second association mode. The complexes have their heavy atoms more or less in the same plane, with the $\varphi\left[\mathrm{X}-\mathrm{C}^{3}-\right.$ $\mathrm{C}^{2}-\mathrm{C}^{1}$ ] dihedral ranging from $-5.0^{\circ}$ to $-176.2^{\circ}$. The

Table 7. LPD-substrate affinity in the complex C5 and energy terms associated with the transition state TS8 as calculated by the B3LYP, QCISD(T) and G3 methods*.

\begin{tabular}{|c|c|c|c|c|c|c|c|c|c|}
\hline \multirow[b]{2}{*}{ LPD } & \multicolumn{3}{|c|}{$\Delta E_{a f f}(\mathrm{C} 5)$} & \multicolumn{3}{|c|}{$\Delta E(\mathrm{TS} 8)$} & \multicolumn{3}{|c|}{$E_{a}(\mathrm{TS} 8)$} \\
\hline & B3LYP & QCISD $(\mathrm{T})$ & G3 & B3LYP & QCISD(T) & G3 & B3LYP & QCISD(T) & G3 \\
\hline $\mathrm{HF}$ & 12.02 & 6.66 & 5.58 & - & - & - & - & - & - \\
\hline $\mathrm{H}_{2} \mathrm{O}$ & 26.02 & 20.04 & 15.34 & 29.90 & 32.34 & 35.67 & 11.54 & 11.63 & 8.31 \\
\hline $\mathrm{H}_{2} \mathrm{~S}$ & 26.53 & 32.81 & 26.30 & 30.98 & 19.52 & 26.85 & 13.14 & 13.29 & 10.45 \\
\hline $\mathrm{NH}_{3}$ & 66.71 & 64.99 & 58.36 & -8.61 & 11.95 & -4.96 & 13.78 & 36.19 & 10.70 \\
\hline
\end{tabular}

*Affinities and energy terms in $\mathrm{kcal} / \mathrm{mol}$ 
protons of the LPD are, however, not necessarily within this plane. Figure 7 depicts the TS7 series of transition states for the first phase, all definitely non-planar, as may be evinced from the values of the $\varphi\left[\mathrm{X}-\mathrm{C}^{3}-\mathrm{C}^{2}-\mathrm{C}^{1}\right]$ and $\varphi\left[\mathrm{H}^{*}-\mathrm{X}-\mathrm{C}^{3}-\mathrm{C}^{2}\right]$ dihedrals.

The second phase of the solvated second pathway (second association mode) involves conversion of complex C5 to complex C2 via the transition state TS8 which corresponds to the transition state TS3 for the second step of the unsolvated second pathway. The TS8 species could not be located for the HF case. Table 7 lists the variously calculated values for the enthalpy terms $\Delta E$ (TS8) and $E_{a}$ (TS8). The energy level $\Delta E$ (TS8) of the transition state TS8 relative to the starting reactants ( 1 plus LPD) follows the order $\mathrm{H}_{2} \mathrm{O}>$ $\mathrm{H}_{2} \mathrm{~S}>\mathrm{NH}_{3}$ with respect to the catalyst. Here again, the LPD does not necessarily lower the effective reaction barrier. Values of the actual activation barrier $E_{a}$ (TS8) met with by the complex $\mathbf{C 5}$ are very different from the $\Delta E(\mathrm{TS} 8)$ values.

Figure S7 (supplementary information) depicts the C5 series of complexes of the LPD with intermediate 3. They are all non-planar, with the $\mathrm{C}^{3}-\mathrm{X}$ bond almost perpendicular to the $C^{1}-C^{2}-C^{3}$ plane and the $\varphi\left[C^{1}-C^{2}-\right.$ $\mathrm{C}^{3}-\mathrm{X}$ ] dihedral ranging from $94.1^{\circ}$ to $106.7^{\circ}$. Figure 8 portrays the TS8 series of transition states for the second phase, where the structures are again non-planar, with the $\varphi\left[\mathrm{C}^{1}-\mathrm{C}^{2}-\mathrm{C}^{3}-\mathrm{X}\right]$ dihedral ranging from $100.7^{\circ}$ to $107.0^{\circ}$.

Figure S8 (supplementary information) depicts the G3 and QCISD(T) energy profiles for the unsolvated and solvated routes involved in the second pathway (first association mode), where relative energies of each stage may be compared, setting the initial stage (species $\mathbf{1}$ for the unsolvated pathway; species $\mathbf{1}$ plus LPD for the solvated pathway) at an energy level of zero.

\subsection{Favoured solvated pathway}

The energies of the transition states TS4, TS5 and TS7 for the rate-determining steps of each of the three solvated pathways described above represent the highest points along each of these three pathways. For all four LPD cases, the relative energies of the three transition states invariably follow the order TS4 > TS5 $>$ TS7. This means the most favoured solvated pathway is the second pathway (second association mode), followed closely by the second pathway (first association mode), while the first pathway is the least favoured among the three. This inference may be compared with the observation that, in the unsolvated isomerization, the second pathway is preferred over the first.

\section{Conclusions}

The three computational strategies employed here to study isomerization of the propargyl cation to the cyclopropenyl cation give largely similar results, where the QCISD(T) and G3 approaches are noticeably close to each other. The following conclusions arise from this investigation:

(i) For the unsolvated isomerization, the two-step second pathway is energetically preferred over the concerted first pathway, with the first step being the rate-determining one for the two-step pathway.

(ii) Lone pair donor affinities for the substrate 1, product $\mathbf{2}$ and intermediate $\mathbf{3}$ all follow the order $\mathrm{NH}_{3}>\mathrm{H}_{2} \mathrm{~S}>\mathrm{H}_{2} \mathrm{O}>\mathrm{HF}$, being related to the number of lone pairs on the donor hetero-atom and to electronegativity of the hetero-atom.

(iii) Energies of the transition states for the ratedetermining steps of the solvated pathways are lowered in the order $\mathrm{HF}<\mathrm{H}_{2} \mathrm{O}<\mathrm{H}_{2} \mathrm{~S}<$ $\mathrm{NH}_{3}$ with respect to the lone pair donor, pointing to the role of LPD affinity, where increase in the number of hetero-atom lone pairs and its electronegativity are defacilitating factors.

(iv) Consistent trends for changes in structure and stability of the LPD-substrate complexes and the transition states follow the order $\mathrm{NH}_{3}>$ $\mathrm{H}_{2} \mathrm{~S}>\mathrm{H}_{2} \mathrm{O}>\mathrm{HF}$.

(v) The preferred pathway for the solvated reaction occurs through the second association mode of the second pathway.

(vi) Calculated equilibrium structures of all species compare well with expected valence bond descriptions. In the LPD- $\mathrm{C}_{3} \mathrm{H}_{3}^{+}$complexes, the LPD generally occurs out of the plane of the C1-C2-C3 moiety.

(vii) Most of the solvated transition states are 'later' than their unsolvated counterparts. Geometrical indicators for transition state position along the reaction coordinate agree well with predictions of the Hammond's postulate based on the energetics of the one-step processes.

\section{Supplementary information}

Tables $\mathrm{S} 1-\mathrm{S} 2$ and figures $\mathrm{S} 1-\mathrm{S} 8$ referred to in the text and mentioned as supplementary information may be retrieved from the journal website (www.ias.ac.in/ chemsci). 


\section{Acknowledgements}

The authors thank the Special Assistant Program of the University Grants Commission (UGC) to this Department for computational facilities. Special thanks are due to Dr. G N Sastry of the Indian Institute of Chemical Technology, Hyderabad for his kind encouragement and support.

\section{References}

1. Radom L, Hariharan P C, Pople J A and Schleyer P V R 1976 J. Am. Chem. Soc. 9810

2. Raghavachari K, Whiteside R A, Pople J A and Schleyer P V R 1981 J. Am. Chem. Soc. 1035649

3. Cameron A, Leszczynski J, Zerner M C and Weiner B 1989 J. Phys. Chem. 93139

4. Li W K and Riggs N V 1992 J. Mol. Struct. (Theochem) 257189

5. Herbst E, Adams N G and Smith D J 1983 J. Astrophys. 269329

6. Herbst E, Adams N G and Smith D J 1984 J. Astrophys. 285618

7. Adams N G and Smith D J 1987 J. Astrophys. 317 L25

8. Lepp S and Dalgarno A J 1988 J. Astrophys. 324553

9. Turner B E 1989 J. Astrophys. 347 L39

10. Lee T J, Willetts A, Gaw J F and Handy N C 1989 J. Chem. Phys. 904330

11. Wyss M, Riaplov E and Maier J P 2001 J. Chem. Phys. 11410355

12. Kunde V G, Aikin A C, Hanel R A, Jennings D E, Maguire W C and Samuelson R E 1981 Nature 292 686

13. McEwan M J, McConnell C L, Freeman C G and Anicich V G 1994 J. Phys. Chem. 985068
14. Smyth K C, Lias S G and Ausloos P 1982 Combust. Sci. Technol. 28147

15. Calcotte H F 1981 Combust. Flame 42215

16. Baykut G, Brill F W and Eyler J R 1986 Combust. Sci. Technol. $\mathbf{4 5} 233$

17. Calcotte H F and Gill R J 1984 In Soot formation in combustion, H. Bockborn, Ed. (Springer, Berlin), p. 471

18. Ozturk F, Baykut G, Moini M and Eyler J R 1987 J. Phys. Chem. 914360

19. Lui G X, Li Z S, Ding Y H, Fu Q, Huang X R, Sun C C and Tang A C 2002 J. Phys. Chem. A 10610415

20. Wong M W and Radom L 1989 J. Am. Chem. Soc. 111 6976

21. Maluendes S A, McLean A D, Yamashita K and Herbst E 1993 J. Chem. Phys. 992812

22. Datta A, Hrovat D A and Borden W T 2008 J. Am. Chem. Soc. 1306684

23. Gonzalez-James O M, Zhang X, Datta A, Hrovat D A, Borden W T and Singleton D A $2010 \mathrm{~J}$. Am. Chem. Soc. 13212548

24. Krapp A, Bickelhaupt F M and Frenking G 2006 Chem.-Eur. J. 129196

25. Jose D and Datta A 2011 Cryst. Growth Des. 113137

26. Becke A D 1988 Phys. Rev. A 383098

27. Becke A D 1993 J. Chem. Phys. 985648

28. Lee C, Yang W and Parr R G 1988 Phys. Rev. B 37 785

29. Dewar M J S, Zoebisch E G, Healy E F and Stewart J J P 1985 J. Am. Chem. Soc. 1073902

30. Frisch $\mathrm{M} \mathrm{J}$ et al. 2001 Gaussian 98 Revision A.11.2, Gaussian Inc., Pittsburgh, PA

31. Curtiss L A, Raghavachari K, Refern P C, Rassolov V and Pople J A 1998 J. Chem. Phys. 1097664

32. Hammond G S 1955 J. Am. Chem. Soc. 77334

33. Pachuau Z and Lyngdoh R H D 2004 J. Chem. Sci. 11683

34. Dkhar P G S and Lyngdoh R H D 2005 Indian J. Chem. B 442138 